\title{
THE NOISE POLLUTION IN NATURE PROTECTED AREA OF THE PERGUSA LAKE
}

\author{
F. PATANIA, A. GAGLIANO, F. NOCERA \& A. GALESI \\ Energy and Environment Division of D.I.I.M., Engineering Faculty, Catania University, Italy.
}

\begin{abstract}
Generally, people demonstrate a strong awareness of the noise effects which interfere with the human habitat; consequently there are new public laws and regulations to control emissions of noise in these environments. However, there is an inadequate attention towards human-induced noise pollution that damage animal habitats in wildlife reserves and it is one of many factors contributing to the depletion of wildlife populations. The aim of this applied research is to evaluate both the acoustical climate in the 'Natural Reserve of Pergusa' and the negative effects on the habitat of wildlife populations due to the noise emissions coming from Pergusa Autodrome that lies on the boundaries of the Pergusa Lake.

The research has been developed through the following phases:
\end{abstract}

- Campaign of acoustical measurements for the characterization of ambient noise climate in the Reserve Area both during car race event and without car race event;

- Analysis and data processing of acoustical measurements;

- Adoption of an acoustical simulation model to calculate the noise levels predicted during motor race;

- Analysis and comparison of simulated noise levels and measured noise levels;

- Drawing of isophone curves in GIS environment to visualize the zones exposed to high levels of noise.

On the bases of the results obtained, the paper shows that the noise level measured or predicted inside the Reserve Area could cause strong and negative interferences with the habitat of wildlife population.

Keywords: acoustical climate, animal habitats, noise pollution, wildlife reserve.

\section{INTRODUCTION}

The Pergusa Lake is found in the province of Enna, in a vast growing grain zone of Sicily. This lake is one of the few natural lakes that remain on an island famous in antiquity for its wetlands. A panoramic view of Pergusa lake is shown in Fig. 1.

The Pergusa's water basin was formed in the prehistoric age because of the sudden sinking of the earth's rock layers. The lake is fed only by rainwater and underground sources, which are slightly salinated and sulphurous. Many mythological legends indicate the Pergusa Lake as the site of the Rape of Prosperpine (Prosperpine is an ancient Roman goddess whose story is the basis of the myth of Springtime).

The territory surrounding the Pergusa lake represents, both for the strategic geographical position and its characteristic of 'wet zone', an important resting and wintering for migratory birds.

The lake is one of the most important area in Sicily that hosts the winter ducks, coots, swans, herons, flamingos, cranes, and many other water species.

For these reasons, since 1991 the area surrounding the lake has been classified as a regional nature reserve. On 12 July 2001, the 'special wildlife reserve of Pergusa Lake' was established because of its features of lacustral area in an environment of remarkable naturalistic importance (Fig. 2).

(C) 2011 WIT Press, www.witpress.com

ISSN: 1755-7437 (paper format), ISSN: 1755-7445 (online), http://journals.witpress.com

DOI: 10.2495/DNE-V6-N1-52-67 

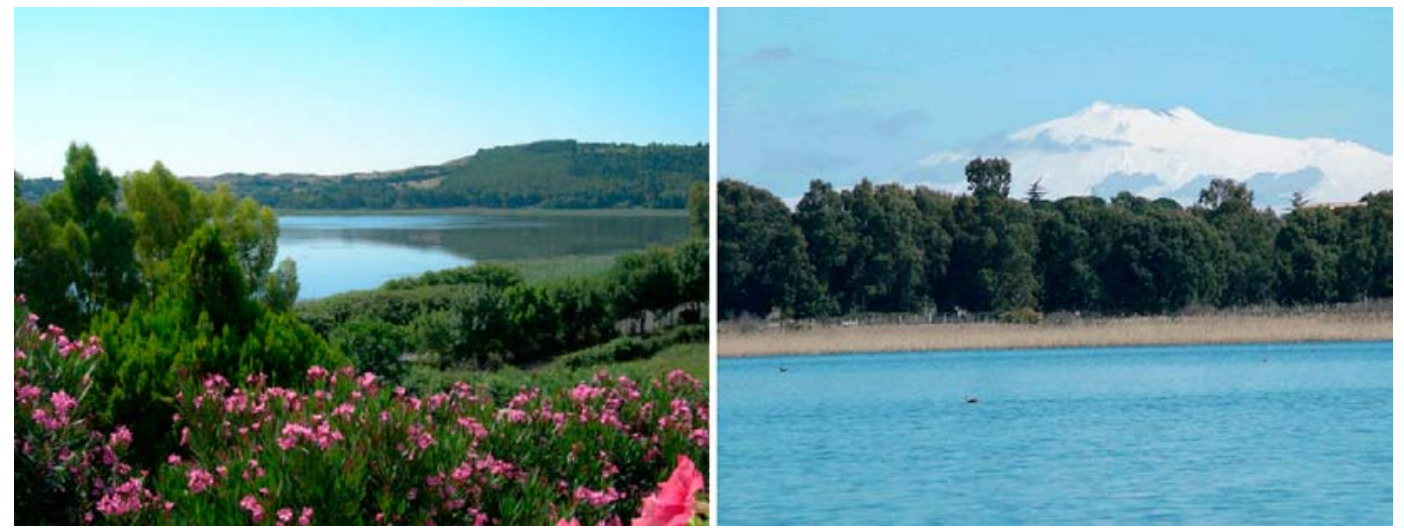

Figure 1: Views of Pergusa lake.

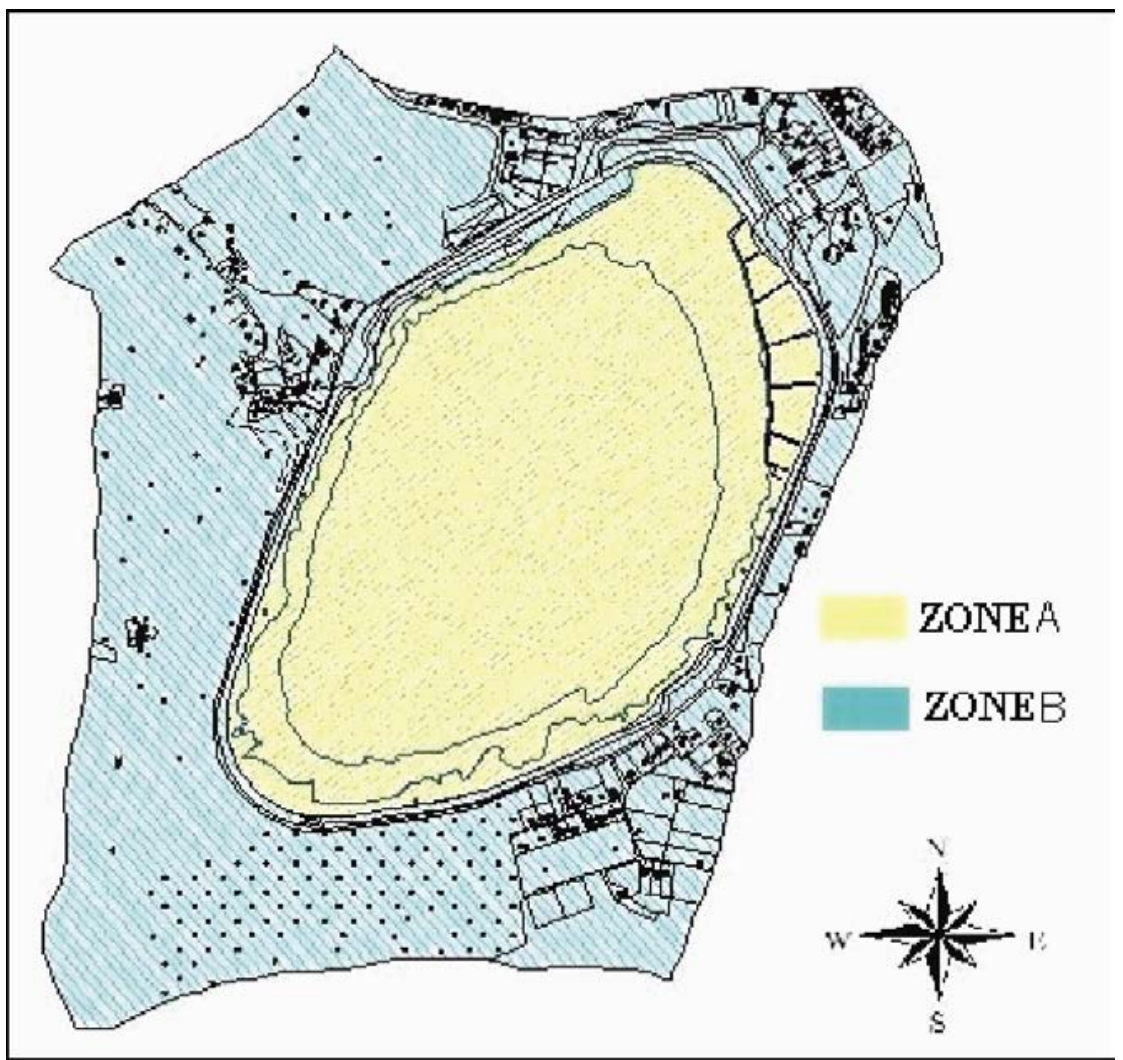

Figure 2: Map of the natural reserve of Pergusa.

Moreover, the reserve was classified by UE as 'Zones of Particular Environmental Protection and Sites of CEE Importance' in the European Directives 92/43/CEE (Habitat Directive) and in the European Directives 85/337/CEE. 
The natural reserve covers an area over 402.5 hectares (246.1 in A zone and 251.2 in B zone).

Around the reserve area it is found the Pergusa's Autodrome built along the entire perimeter of the lake (three-miles) in the 1960s (Fig. 3).

Since 1961, when the first Formula 1 race took place, the Autodrome has hosted numerous motor races.

Therefore, it is reasonable to think that some interferences and conflicts between the racetrack and the surrounding environment of the Natural Reserve could occur. For this reason, the aim in protecting the wildlife environment, the Regional Environment Authority authorizes the racetrack activity only during a specific period of the year: from 15th March to 30th October.

One of possible factors that damage the animal habitat in wildlife reserves is the noise pollution produced by the car races that alters the behaviour of the animals or interferes with their life function.

The negative effects for the animals are loss of usable habitat, increased energy consumption, lower food intake and resting time and in consequence an impaired body condition [1] These negative effects may be classified as 'damage' or 'disturbance' [2].

The damage is an event that causes harm to health and alters reproduction, survivorship, habitat use, distribution, abundance or genetic distribution. The 'disturbance' is an event that causes detectable changes in the behaviour that indicates aversion. Boere's definition of disturbance is 'any situation in which a bird behaves differently from its preferred behaviour' [3].

Many researches show that birds, just like humans, produce, learn, and use complex acoustic signals for communication. Birds rely on their auditory systems for basic survival, they use auditory signals to choose potential mates, find prey, avoid predators, and defend their territories.

In their environment birds must be able to discriminate their own 'voices' and the songs of other species from any background noise [4]. In many cases sounds must be transmitted over very large distances and must also be sufficiently powerful to carry above the ambient noise level due to both climatic and biotic factors in the environment.

The sound production of several bird species has been measured to peaks of about $90-95 \mathrm{~dB}$ and it is generally higher for larger birds [5]. Studies of budgerigars indicate that at the best frequency $(2.86 \mathrm{kHz})$ sound production needs to exceed background by $18-20 \mathrm{~dB}$ for detection [6].

The vocalization, detected between the signaller and the receiver, will increase depending on the source intensity, the amount of masking and the rate of attenuation. The rate of attenuation of the
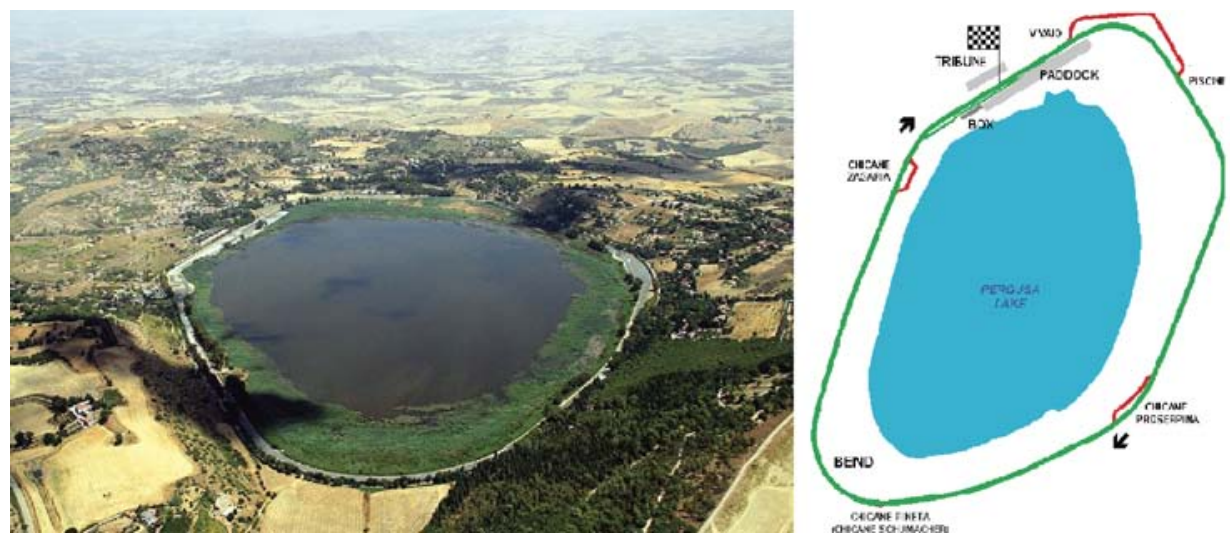

Figure 3: View of motor racing circuit. 
sound is affected by the surroundings, and its estimation ranges from $5 \mathrm{~dB} / \mathrm{m}$ for a bird $10 \mathrm{~m}$ above the ground in an open field to $20 \mathrm{~dB} / \mathrm{m}$ for a bird on the ground in a coniferous forest [7]. The hearing range of birds is from below $50 \mathrm{~Hz}$ (infrasound) to above $20 \mathrm{kHz}$ (ultrasound) with maximum sensitivity between 1 and $5 \mathrm{kHz}$.

One of the earliest studies to find a 'highway effect' on bird populations was carried out by Räty [8], who measured the numbers of birds in forests at a distance up to $1 \mathrm{~km}$ from the road: he discovered a $2 / 3$ reduction in numbers of birds at distance of $250 \mathrm{~m}$ and some reduction at $500 \mathrm{~m}$.

\section{THE NOISE CLIMATE OF THE RESERVE AREA}

In the Reserve Area there are many noise sources related to human activities placed near the lake such as restaurants, hotels, summer residences and so on. Moreover, in summer time some live concerts have taken place in the immediate neighbourhood of the lake.

The Authors have carried out this applied research with the aim to highlight the level of noise impact caused by anthropic noise in the natural habitat of Reserve by the following procedures:

Acoustical characterization of the enquired area, through sound level meter measurements, in absence of motor race event:

- Acoustical characterization of the enquired area, through sound level meter measurements, during the race event.

- Direct observation of bird behaviour during the race events.

- Acoustical characterization of enquired area through a sound propagation model during the motor race events.

- Comparison between the predicted noise levels with measured noise level.

Measurements of sound level have been done in 16 points, uniformly distributed in the proximity of the Autodrome, as shown in Fig. 4, to evaluate the noise pollution.

The surveying campaign has been organised with reference to the Italian regulation that fixes the limit of the environmental noise in the day time (6.00-22.00) and in the night time (22.00-6.00).

In the case of protected area, these law limits are:

- in the day period $\mathrm{L}_{\mathrm{Aeq}, \mathrm{D}}=50 \mathrm{dBA}$.

- in the night period $\mathrm{L}_{\mathrm{Aeq}, \mathrm{N}}=40 \mathrm{dBA}$.

The measurements of sound level have been carried out for different days of week and for different hour of day, so to obtain:

- one working day, one Saturday and one Sunday;

- three intervals during day time: from 6.00 to $11.00 \mathrm{~h}$; from 11.00 to $16.00 \mathrm{~h}$ and from 16.00 to $22.00 \mathrm{~h}$;

- one period for the night time, from 22.00 to $6.00 \mathrm{~h}$.

Each measurement carried out has had a length of $15 \mathrm{~min}$.

The energy equivalent sound pressure level has been calculated both in day-time and night-time period by the following formula:

$$
\mathrm{L}_{\text {Aeq, } \mathrm{T}}=\left[\frac{1}{\mathrm{~T}} \sum_{\mathrm{i}=1}^{\mathrm{n}}\left(\mathrm{T}_{\mathrm{M}}\right)_{\mathrm{i}} 10^{0,1 \mathrm{~L}_{\text {Aeq(TM }) \mathrm{i}}}\right]
$$




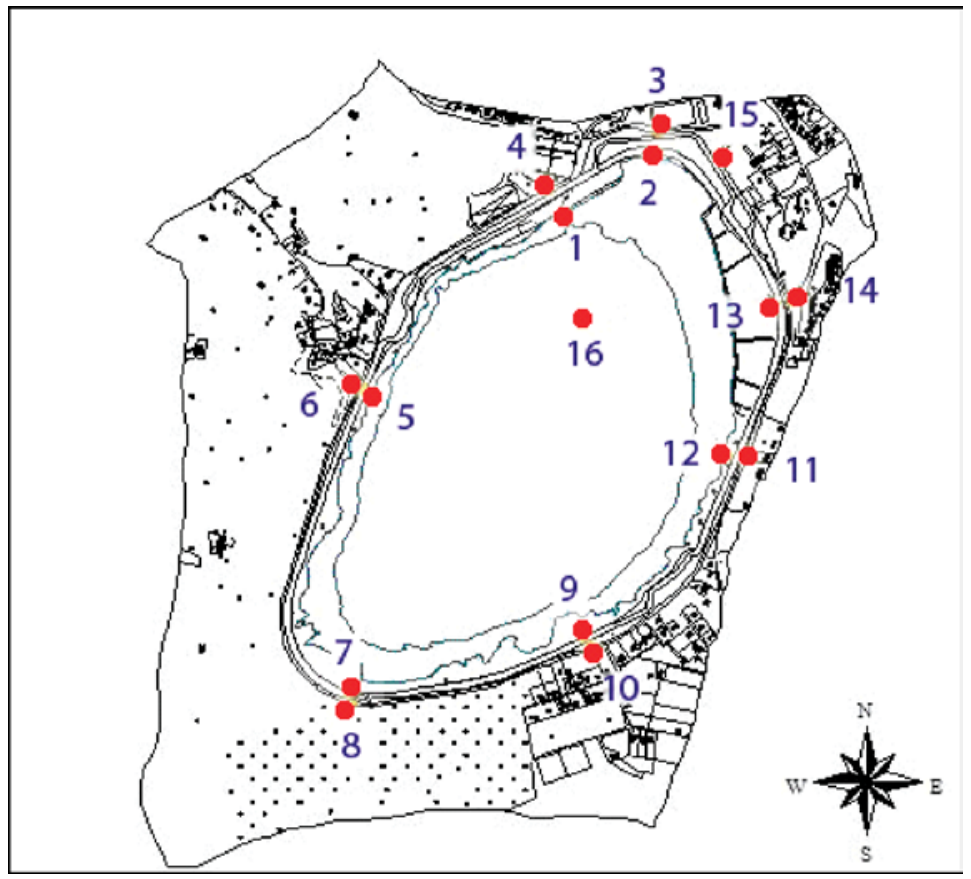

Figure 4: Map of area reserve and measurement points.

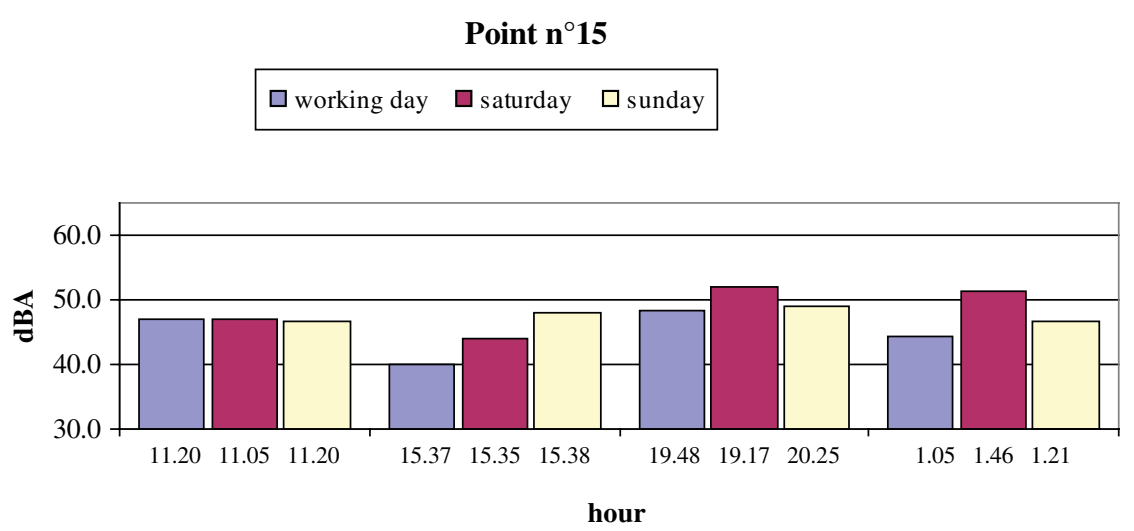

Figure 5: Sample of measurement point.

where $\mathrm{L}_{\text {Aeq,T }}=$ daily energy equivalent sound pressure level; $\mathrm{T}=$ reference period; day-time from 6.00 to $22.00 \mathrm{~h}$; night-time from 22.00 to $6.00 \mathrm{~h} ;\left(\mathrm{L}_{\text {Aeq,TM }}\right)_{\mathrm{i}}=$ measured energy equivalent sound pressure level; $\left(\mathrm{T}_{\mathrm{M}}\right)_{\mathrm{i}}=$ time reference for each measurements.

Figure 5 shows an 'exemplum' of results of $\mathrm{L}_{\text {Aeq,TM }}$ measurements for the point 15 .

Figure 6 shows the average of the measurements results $\left(\mathrm{L}_{\mathrm{Aeq}, \mathrm{T}}\right)$ in each point of measurements both on a working day and a holyday. 


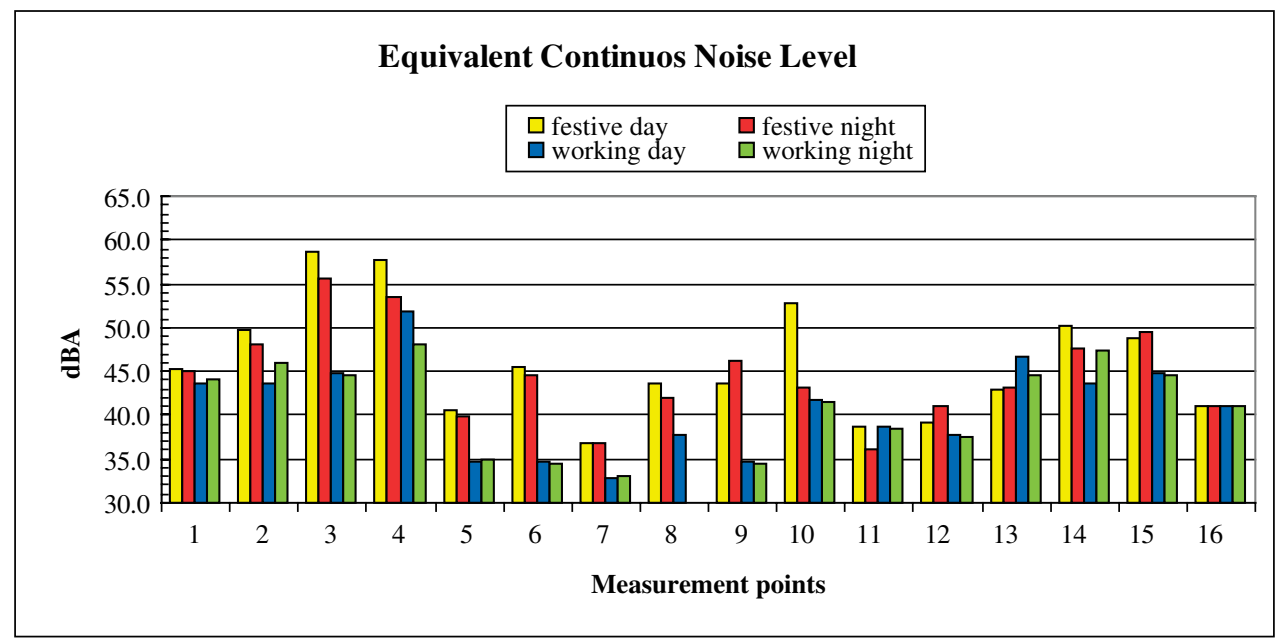

Figure 6: $\mathrm{L}_{\text {Aeq,T }}$ in the measurement points.

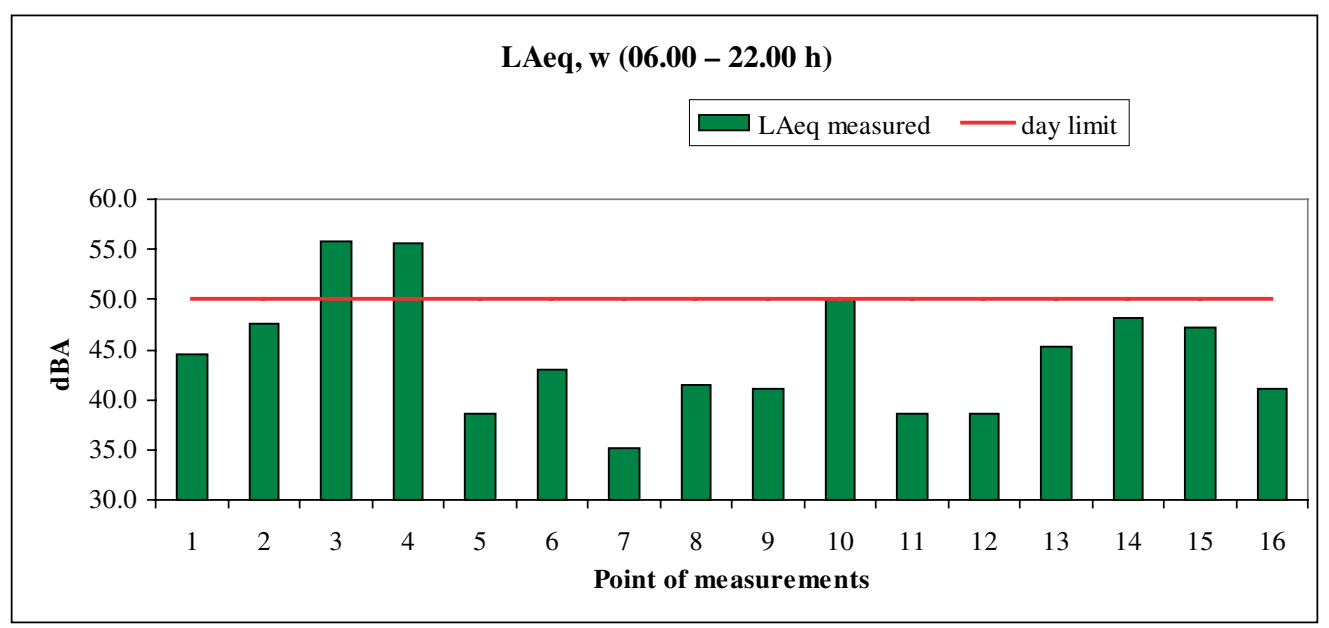

Figure 7: $\mathrm{L}_{\text {Aeq,w }}-$ day period.

For each measurement point the weekly energy equivalent sound pressure level, $\mathrm{L}_{\mathrm{Aeq}, \mathrm{W}}$, has been calculated during the day and the night period by the following formula:

$$
\mathrm{L}_{\text {Aeq, }}=\left[\frac{1}{\mathrm{~N}} \sum_{\mathrm{i}=1}^{\mathrm{n}}\left(10^{0,1 \mathrm{~L}_{\text {Aeq,Ti }}}\right)\right]
$$

where $\mathrm{L}_{\text {Aeq, }}=$ weekly equivalent continuous sound pressure level, for the day or night period; $\mathrm{N}=$ number of day; $\mathrm{L}_{\text {Aeq, } \mathrm{T}}=$ daily equivalent continuous sound pressure level.

Figures 7 and 8 show the $\mathrm{L}_{\text {Aeq,w }}$ in every measurement point. 


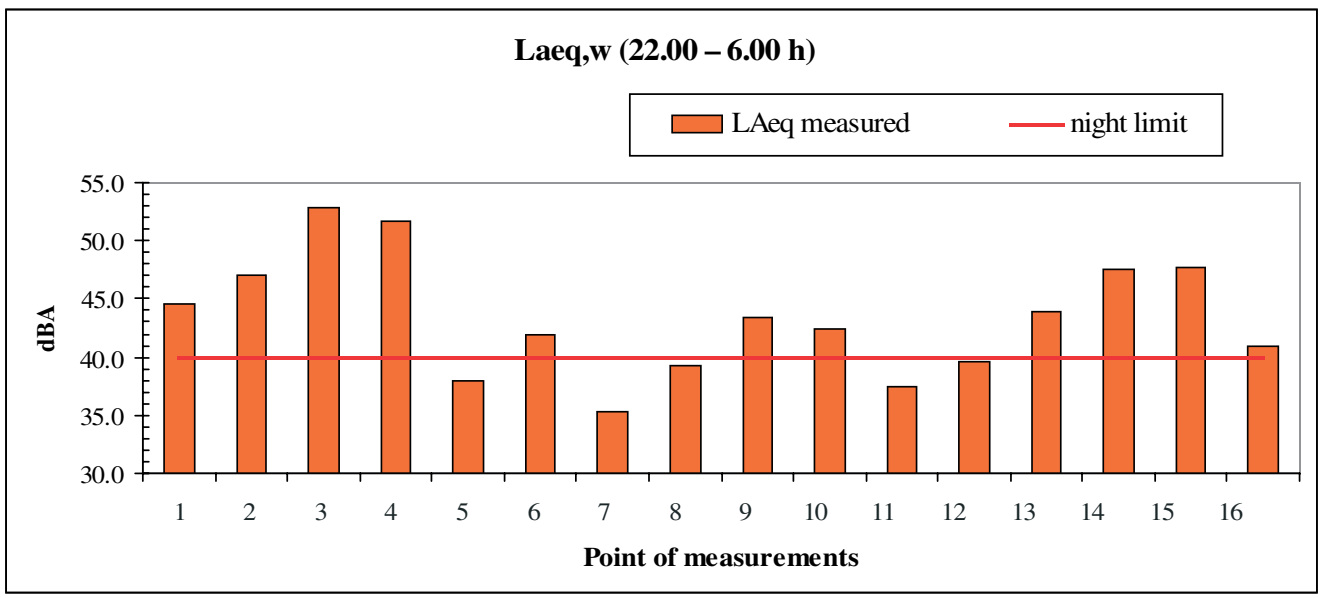

Figure 8: LAeq,w - night period.

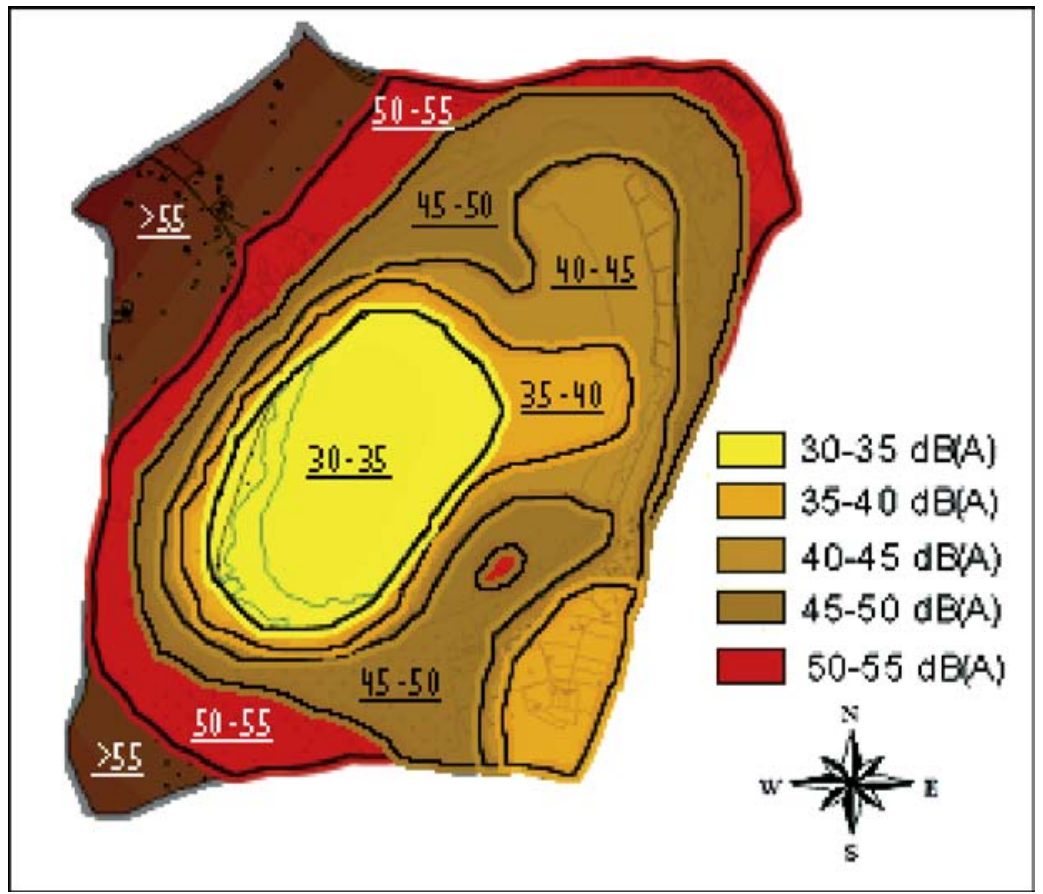

Figure 9: Noise map of isophones during day period $\left(\mathrm{L}_{\text {Aeq,D,w }}\right)$.

Afterwards, the measurements data have been implemented in the GIS software (Geographical Information System) that allows to extrapolate a map with the $\mathrm{L}_{\text {Aeq }}$ isophone, as shown in Figs 9 and 10. These noise maps provide enough information on the actual environmental noise pollution in the reserve area and they could be used for the planning of interventions to control and to reduce noise inside the nature reserve to the limits set by current regulations on noise. 


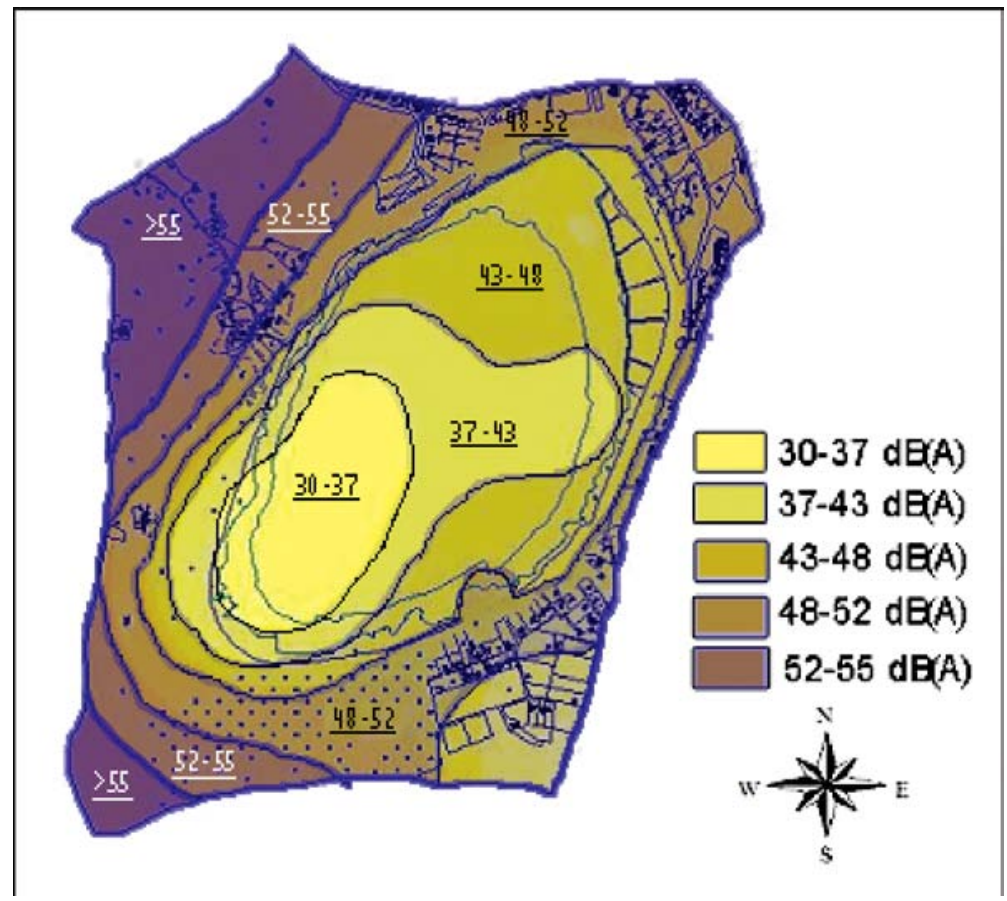

Figure 10: Noise map of isophones during night period $\left(\mathrm{L}_{\text {Aeq, N,w }}\right)$.

Further noise measurements have been carried out during two car races to evaluate the intensity of the noise pollution in the reserve area. Figure 11 and Table 1 show the points of measurements and the values of the $\mathrm{L}_{\text {Aeq }}$ measured.

It is possible to notice that there is a remarkable difference, in each point, between the values of $\mathrm{L}_{\text {Aeq }}$ measured during the two car races monitored. These differences are due to the fact that vehicles with different characteristics of sound power level have participated to the two car races.

The measured values of $\mathrm{L}_{\text {Aeq }}$ have been always higher than the value of $65.0 \mathrm{dBA}$, with the peak value of about $90.0 \mathrm{dBA}$;

The measured values of $\mathrm{L}_{\text {Aeq }}$ have exceeded of 15.0 or $30.0 \mathrm{dBA}$ the values of $\mathrm{L}_{\text {Aeq }}$ measured without car race.

The level of noise pollution produced from the car races is an important source of disturbance for the waterbirds because it modifies their preferred behaviour and leads birds to behave differently than they would in the absence of the races; i.e. during trials and races the waterfowls have interrupted their feeding.

It was observed that usually the Anatidae are scattered over the lake surface where they find the feeding, instead when the car race started the Anatidaes quickly escaped to the lake bank and they hide amongst vegetation. This observed behaviour is probably done with the aim of protecting their nestlings. An example of Anatidaes cluster is shown in Fig. 12.

Also the other birds appeared to be disturbed by the noise, in fact they left the trees and flew away. Disturbance effects go on during all the race duration and only after the end of the race do the waterfowl return to a relaxed behaviour (resting, preening, and feeding). 


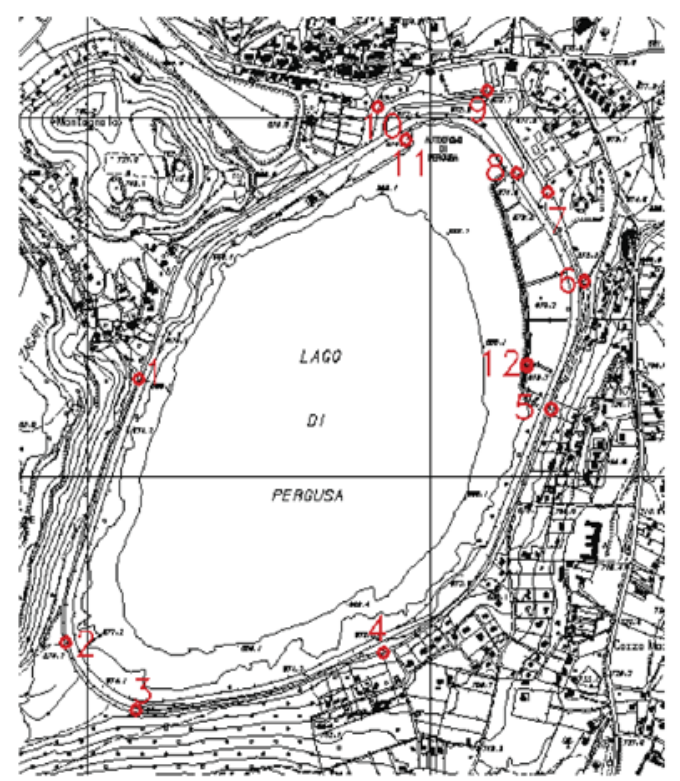

Figure 11: Points of measurements during the car race.

Table 1: The LAeq measurements.

\begin{tabular}{lcc}
\hline Points & $\mathrm{L}_{\mathrm{Aeq}} \mathrm{dB}(\mathrm{A})$ measurements $(15 / 04 / 2007)$ & $\mathrm{L}_{\mathrm{Aeq}} \mathrm{dB}(\mathrm{A})$ measurements $(01 / 07 / 2007)$ \\
\hline 1 & 89.0 & 73.0 \\
2 & 69.0 & 65.0 \\
3 & 88.0 & 73.0 \\
7 & 77.0 & 74.0 \\
8 & 75.0 & 70.0 \\
11 & 88.0 & 72.0 \\
\hline
\end{tabular}
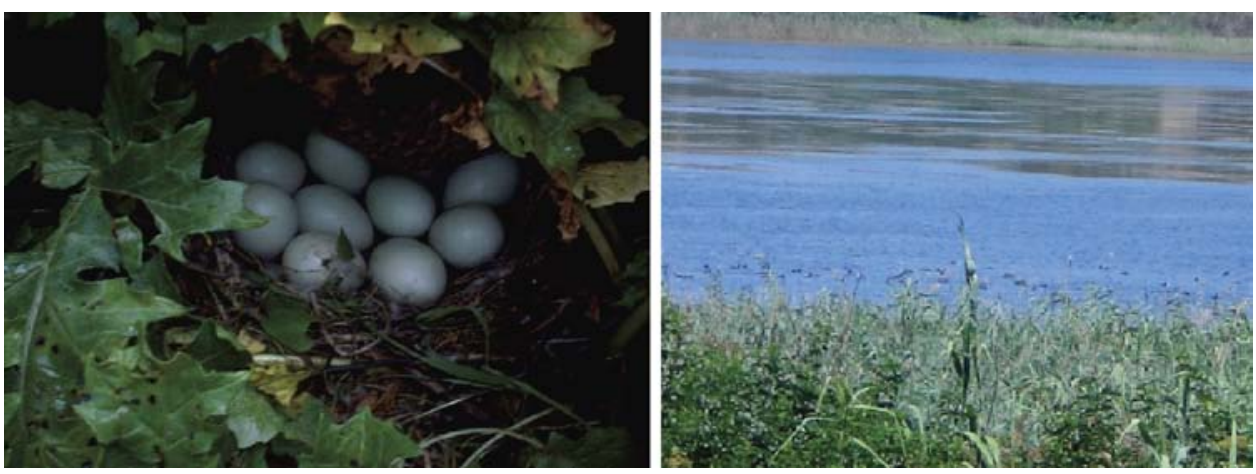

Figure 12: The Anatidae cluster near the lake bank. 
These disturbances are really relevant, in fact, vegetarian birds (Anatidae and passeriformes) need a regular frequency of feeding. Nestlings in particular could die if they don't get fed for a period more than two or three hours long.

With reference to the long-term decline of the population of the species on the site, it has been noted that there are not groups of birds that have definitely abandoned the Reserve Area.

Therefore, the referred observation have allowed to assure that the motor race activities create a disturbance on the wildlife habitat and could create a serious risk for the decline of the population of the species on the site. These risks are particularly serious during the nesting and breeding period (from March to October).

\section{THE MODEL OF NOISE PROPAGATIONS}

The model of noise propagation needs to define:

- type of acoustic source and its sound power level during race conditions;

- propagation path;

- acoustic attenuations.

The source of noise has been schematised as a source line that is the trajectory of a moving point source, it has been represented by a set of straight line segments (poly-line) [9].

The propagation path is the geometrical cross-section that represents the transmission path along which the acoustical waves are transmitted from a point source towards a receiver point. The angle of view of the propagation sector is the angle between the lines from the receiver to both ends of the source line segment.

The point Source Power Level $\left(\mathrm{L}_{\mathrm{W}}\right)$ per 1/1 octave band is calculated from the following expression:

$$
\mathrm{L}_{\mathrm{W}}=\mathrm{L}_{\mathrm{W}, 0}+\Delta \mathrm{L}_{\mathrm{W}}
$$

where $\mathrm{L}_{\mathrm{W}, 0}$ is a constant and $\Delta \mathrm{L}_{\mathrm{W}}$ is a function of angle $\phi$, which represents horizontal directivity of the point source.

The equivalent sound level generated by the constant flow of point sources can be expressed as [10]:

$$
\mathrm{L}_{\text {Aeq }}=\mathrm{L}_{\mathrm{W}, 0}+10 \log \frac{Q}{v}-A_{\text {line }}
$$

where $Q$ is the number of point sources passing per unit time, $v$ is the speed of the point sources.

$Q / v$ is the average number of point sources per unit length and $\mathrm{A}_{\text {line }}$ is the line-source attenuation:

$$
\mathrm{A}_{\text {line }}=\mathrm{A}_{\mathrm{div}}+\mathrm{A}_{\mathrm{atm}}+\mathrm{A}_{\mathrm{gr}}+\mathrm{A}_{\mathrm{bar}}+\mathrm{A}_{\text {misc }}
$$

where $A_{\mathrm{div}}=$ the attenuation due to geometrical divergence; $A_{\mathrm{atm}}=$ the attenuation due to atmospheric absorption; $A_{\mathrm{gr}}=$ the attenuation due to the ground effect; $A_{\mathrm{bar}}=$ the attenuation due to screening structures; $A_{\text {misc }}=$ the attenuation due to miscellaneous other effect.

The terms $\mathrm{L}_{\mathrm{W}, 0}+10 \log (Q / v)$ represented the sound power level per unit length.

\subsection{Attenuation due to geometrical divergence}

It is possible to express the attenuation due to geometrical divergence as [11]:

$$
A_{d i v}=10 \log \left(\frac{\Delta \vartheta}{4 \pi d_{o}}\right)
$$


$\Delta \theta=$ angle of view from the receiver to the segment; $\mathrm{d}_{0}=$ shortest distance from receiver to straight line containing the line source segment. Fig. 13 shows the parameters for the calculation of geometrical divergence.

For greater distance it is also possible to write: $\theta_{2}-\theta_{1} \approx l / d_{0} \cos \theta \approx l / d$.

The terms $b$ and $l$ represent the dimension of each segmented source $(b<l)$.

\subsection{Attenuation due to atmospheric absorption}

The attenuation for air absorption may be calculated from the method outlined in ISO 9613-2 [12]:

$$
A_{\text {atm }}=\alpha(f) \frac{\mathrm{d}}{1000}
$$

where $\alpha$ is the coefficient of atmospheric attenuation calculated as a function of temperature and humidity according to ISO 9613-1 [13]; $d$ is the distance through which the sound is propagating.

\subsection{Attenuation due to ground effect}

Ground attenuation is primarily the result of the sound reflected from the ground surface interfering with the sound propagating directly from source to receiver. The extent of this attenuation depends on the type of ground cover between the source and receiver [14].

The level of ground attenuation is also dependent on the presence of barriers in the area, thus $A_{g r}$ and $\mathrm{A}_{\mathrm{bar}}$ must be considered together.

To determine the level of ground attenuation the propagation path is subdivided into three separate regions; the source region, the middle region and the receiver region.

The acoustical properties of different ground surfaces are reported in Table 2.

The overall attenuation due to ground effect, in favourable conditions may be calculated from:

$$
A_{\mathrm{gr}}=\mathrm{A}_{\mathrm{s}, \mathrm{F}}+\mathrm{A}_{\mathrm{m}, \mathrm{F}}+\mathrm{A}_{\mathrm{r}, \mathrm{F}}
$$

where $\mathrm{As}, \mathrm{F}, \mathrm{Am}, \mathrm{F}$ and $\mathrm{Ar}, \mathrm{F}$ represent the attenuation due to ground effect in the source, middle and receiver zone.

Each term in eqn (8) is calculated in function of:

- the source heights $\left(h_{\mathrm{s}}\right)$ and receiver heights $\left(h_{\mathrm{r}}\right)$;

- the use of a ground factor G, which is defined for three surface types, hard, soft and mixed;

- the distance between source and receiver, perpendicular to the average ground profile in metres.

\subsection{Attenuation due to diffraction}

The attenuation due to barrier may be calculated from the equation $[15,16]$

$$
\begin{gathered}
A_{b a r}=5+20 \log \frac{\sqrt{2 \pi|N|}}{\tanh \sqrt{2 \pi|N|}} \\
N= \pm \frac{2}{\lambda}(\delta)
\end{gathered}
$$




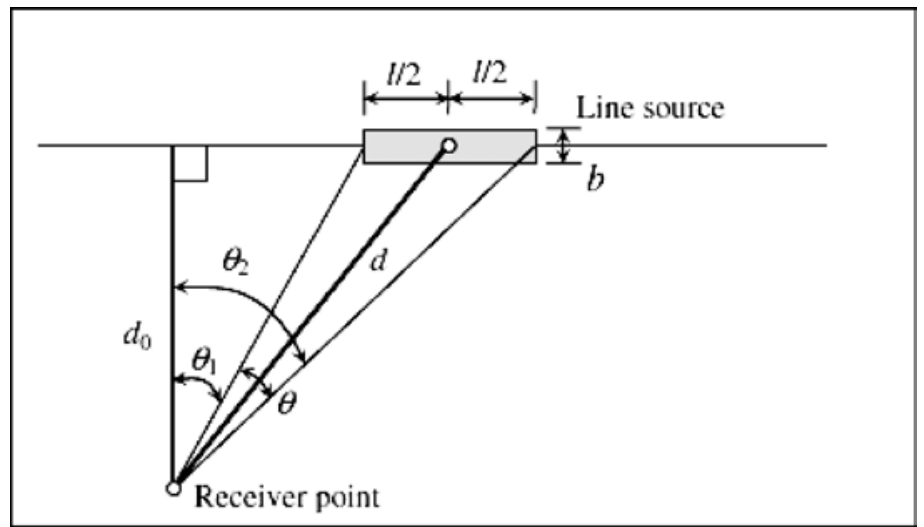

Figure 13: Geometrical attenuation using a segmented source.

Table 2: Values for $\mathrm{G}$ for various ground surface types.

\begin{tabular}{lll}
\hline Surface & Example of surface & Value \\
Hard & Concrete, water, etc. & $\mathrm{G}=0$ \\
Soft & Grass, vegetation, etc. & $\mathrm{G}=1$ \\
Mixed & Both hard and soft ground & $0<\mathrm{G}<1$ \\
\hline
\end{tabular}

$\lambda$ is the wavelength, $\delta$ is the difference between diffracted path and direct path of sound ray.

$$
\mathrm{A}_{\mathrm{bar}}=0 \quad \text { if } \mathrm{N}<\& \text { minus; }-0.2
$$

For $\mathrm{N}>12.5$, experimental data show that there is an upper limit of $24 \mathrm{~dB}$.

If the average ground profile creates a natural barrier between source and receiver, a correction has to be applied to account for the subsequent attenuation.

\subsection{Attenuation due to miscellaneous other effect}

The term $\left(A_{\text {misc }}\right)$ has been referred to propagation through foliage only if it is sufficiently dense to fully block the view along the propagation path preventing direct transmission of sound to receiver.

Approximate values for the excess attenuation from dense foliage are listed in ISO 9613-2. Attenuation due to short-term wind effects is not considered.

\subsection{Application of the proposed model}

The proposed model of noise propagation is based on the hypothesis that the acoustical energy, for each receiver, is given by the summation of energetic contribution emitted by each source line of the race circuit.

The Autodrome circuit has been divided in 50 straight tracts. Each tract has been considered as an acoustic line source. The emission of acoustic energy of each straight line source has been placed at $0.5 \mathrm{~m}$ above the ground.

The Reserve Area has been divided into a set of square mesh of $100.0 \mathrm{~m} \times 100.0 \mathrm{~m}$, obtaining 148 sub-areas. Each sub-area has been considered as a homogeneous receiver and classified with a number, from 1 to 148 , (Fig. 14). 


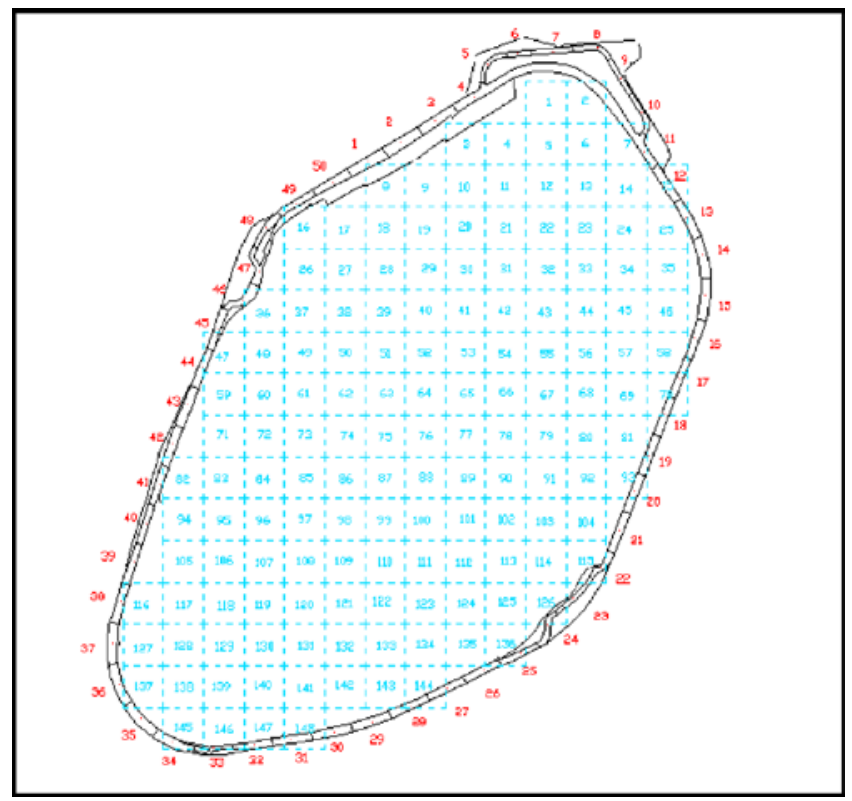

Figure 14: Mesh of calculus.

For each couple $\mathrm{i}-\mathrm{j}$ receiver-source line, the attenuations along the sound path have been evaluated. The term $A_{\text {div }}$ has been calculated both in function of the normal distance $\mathrm{d}_{\mathrm{oi}, \mathrm{j}}$ and using trigonometric relations to define the angles $\theta_{1}$ and $\theta_{2}$. The other attenuations $\left(A_{b a r}, A_{g r}\right.$, etc. $)$ have been calculated in function of the effective geometry. All the geometrical data have been extrapolated from GIS software.

All the previous equations have been implemented in the GIS software, so for each receiver the Sound Level Pressure $\mathrm{L}_{\mathrm{p}, \mathrm{ij}}$ has been calculated. The proposed procedure has been applied for each source line, therefore the total SPL $\left(\mathrm{L}_{\mathrm{p}, \mathrm{i}}\right)$ in each receiver is obtained from the logarithmic summation of the SPL coming from each single source line.

$$
\mathrm{L}_{\mathrm{p}, \mathrm{i}}=10 \log \left[\sum_{\mathrm{j}} 10^{\mathrm{L}_{\mathrm{p}, \mathrm{ij}} / 10}\right]
$$

\section{RESULTS AND DISCUSSION}

The proposed model of noise propagation has been applied for the prevision of the noise pollution in the Reserve Area. The noise source has been defined by means of the sound power level of the sports cars, the vehicular flow and the velocity.

Such parameters have been assumed with reference to the two races occurred during the campaign of acoustic measurements.

The sound power level for two typologies of race, the vehicular low and the velocity have been summarised in Table 3.

The results obtained from simulation have been compared with the data coming from measurements. The comparison has been reported in Table 4. 
Table 3: Parameters of noise source.

\begin{tabular}{lccc}
\hline Type & $\mathrm{L}_{\mathrm{w}, 0}[\mathrm{~dB}]$ & $\mathrm{Q}[$ vehic/s] & $\mathrm{V}[\mathrm{m} / \mathrm{s}]$ \\
\hline Race a) & 110 & 0.01857 & 41.66 \\
Race b) & 100 & 0.01857 & 41.66 \\
\hline
\end{tabular}

Table 4: Comparison between measurements and predicted data.

\begin{tabular}{lccc}
\hline Measurements points & $\begin{array}{c}\text { Number of receiver } \\
\text { (sub-area) }\end{array}$ & Measured $\mathrm{L}_{\text {Aeq }} \mathrm{dB}(\mathrm{A})$ & Calculated $\mathrm{L}_{\text {Aeq }} \mathrm{dB}(\mathrm{A})$ \\
\hline 1 & 47 & 73.0 & 74.8 \\
2 & 137 & 65.0 & 64.0 \\
3 & 145 & 73.0 & 74.7 \\
4 & 135 & 61.0 & 63.4 \\
6 & 35 & 73.0 & 70.8 \\
7 & 15 & 74.0 & 71.5 \\
8 & 7 & 70.0 & 70.5 \\
11 & 1 & 72.0 & 71.7 \\
12 & 58 & 54.0 & 61.4 \\
\hline
\end{tabular}

It is possible to notice that:

- the values of $\mathrm{L}_{\text {Aeq }}$ (measured or predicted) have significant differences for each point of measurements for the effect of the different contribute of the attenuations along each path source-receiver;

- the differences between measured values and predicted values lie in the range of $\pm 2.0 \mathrm{dBA}$ that could be considered acceptable for the scope of the study;

- these errors are obviously due both for the approximation of the site geometry and for the not exact prediction of the sound attenuation.

One of our aims has been to verify the respect of Italian regulation on the matter that fixes the $\mathrm{L}_{\text {Aeg }}$ limit of $50 \mathrm{dBA}$ during the day-time period (from 6.00 to $22.00 \mathrm{~h}$ ). Fig. 15 shows the calculated value of $\mathrm{L}_{\text {Aeq }}$ during day time (6.00-22.00).

For the calculation of $\mathrm{L}_{\text {Aeq }}$, two 'homogeneous' periods have been considered:

- a first period (for a time about $8 \mathrm{~h}$ ) that include all the race activities (speed tests, qualifying race, race). For the first period, the authors have utilized the values of $\mathrm{L}_{\mathrm{Aeq}}$ coming from acoustic proposed model;

- a second period, for the remaining day-time period $(8 \mathrm{~h})$. For this period, the authors have utilized the values of $\mathrm{L}_{\text {Aeq }}$ coming from measurements (in the absence of motor race).

The obtained values of $\mathrm{L}_{\text {Aeq }}$ for the day period has been implemented in the GIS software, that by means its algorithm permits to extrapolate the $\mathrm{L}_{\text {Aeq }}$ isophone curves in the Reserve Area.

The noise map of $\mathrm{L}_{\text {Aeq }}$ isophones show:

- a radial trend that results coherent with the geometry of the racetrack.

- the barrier effect caused by the natural vegetation along the shore of lake.

The values of $\mathrm{L}_{\text {Aeq }}$ overcome the law limit from 25.0 to $40.0 \mathrm{dBA}$ or more, overall the Reserve Area. 

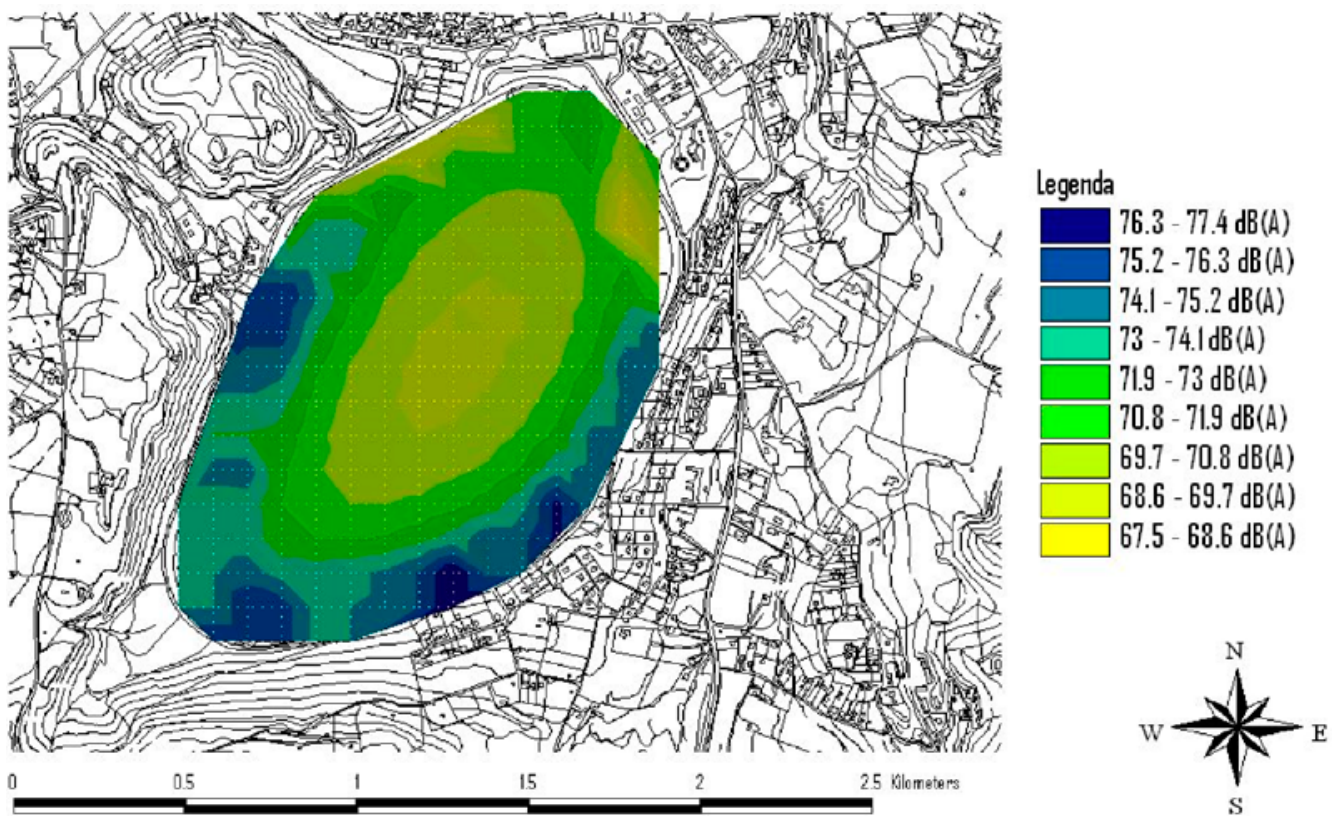

Figure 15: $\mathrm{L}_{\text {Aeq }}$ during day time (6.00-22.00).

Moreover, the results obtained both by measurements and by proposed model have been compared with other experimental measurements executed in different racetrack [5]. These measurements indicate values of $\mathrm{L}_{\mathrm{Aeq}}$ ranging between 70.0 and $75.0 \mathrm{~dB}(\mathrm{~A})$, that are fully comparable with the results illustrated in this paper.

\section{CONCLUSIONS}

The results of the study have shown that for the effect of the antropic activities, even without race events, the law limit of $\mathrm{L}_{\text {Aeq }}$ has been overcome in some of the measurement points. The $\mathrm{L}_{\text {Aeq }}$ measured overcome the law limit from 6.0 to $7.0 \mathrm{dBA}$ during the day period and from 5.0 to $15.0 \mathrm{dBA}$ during the night period.

During the race event, the values of $\mathrm{L}_{\text {Aeq }}$, coming from simulations, overcome the law limit from 25.0 to $40.0 \mathrm{dBA}$ or more, in all the measurement points.

The comparison between measurements data and predicted data of LAeq has confirmed the reliability of the proposed noise propagation model.

The discovered noise pollution does not only disrespect the acoustic regulations but also interferes with the 'status' and the activities of the water birds that live in the reserve. In fact, during the motor race the intensity of the sound mask the important biological signals of the birds, interfering with their ability to communicate effectively.

These observations surely confirm the detrimental effect on the normal activity of the water birds, particularly with the breeding biology.

It is necessary to investigate more and more the ethology of the migratory birds that are hosted in the natural reserve, in such way that it will be possible to define the periods, during the day and during the year when the race cars produce the minor interferences with the 'life' of the reserve. 
Considering that the maximum influx of migratory birds occurs in the months of March, April, September and October it would be better to avoid the races in these periods.

On the basis of the previous considerations, the Authors really believe that it is necessary to foresee appropriate measures of mitigation so as to provide adequate protection from the noise to the reserve area and satisfy the expectation of enthusiasts that want to see the motor races.

\section{REFERENCES}

[1] Komenda-Zehnder, S., Cevallos, M. \& Bruderer, B., Effects of disturbance by aircraft overflight on waterbirds. Proceedings of the 26th International Bird Strike Committee Meeting, Warsaw, 5-9 May 2003.

[2] Bowles, A.E., Responses of wildlife to noise. Wildlife and Recreationists: Coexistence through Management and Research, eds R.L. Knight \& K.J. Gutzwiller, Island Press: Washington DC, pp. 109-156, 1995.

[3] Blanc, R., Guillemain, M., Mouronval, J.-B., Desmont, D. \& Fritz, H., Effects of nonconsumptive leisure disturbance to wildlife. Revue D'Ecologie, 61(2), pp. 117-134, 2006.

[4] Dooling, R.J., Auditory perception in birds. Acoustic Communication in Birds, Vol. 1, Academic Press: New York, pp. 95-129, 1982.

[5] Brackenbury, J.H., Power capabilities of the avian-producing system. Journal of Experimental Biology, 78, pp. 163-166, 1979.

[6] Cho, D.S., Mun, S., Study to analyze the effects of vehicles and pavement surface types on noise. Applied Acoustics, 69, pp. 1120-1128, 2008. doi:10.1016/j.apacoust.2007.06.004

[7] Marten, K. \& Marler, P., Sound transmission and its significance for animal vocalization. Behavioral Ecology and Sociobiology, 2, pp. 271-290, 1977. doi:10.1007/BF00299740

[8] Reijnen, M.J.S.M., Thissen, J.B.M. \& Bekker, G.J., Effects of road traffic on woodland breeding bird populations. Acta Ecologia/Ecologia Generalis, 8, pp. 312-313, 1987.

[9] Harmonoise Work Package 2. Reference model, HAR29TR-041118-TNO10.doc; December 2004.

[10] ISO 9613-1. Acoustics - attenuation of sound during propagation outdoors - Part 1: calculation of the absorption of sound by the atmosphere; 1993.

[11] Kurze, U.J. \& Anderson, G.S., Sound attenuation by barriers. Applied Acoustics, 4, pp. 35-53, 1971. doi:10.1016/0003-682X(71)90024-7

[12] Baistrocchi, C., Rocco, L., A calculation Model of Height and Length of Traffic Noise Barriers. Internoise $2001-2001$.

[13] Cho, D.-S., Kim, J.-H., Choi, T.-M., Kim, B.-H. \& Manvel, D., Highway traffic noise prediction using method fully compliant with ISO 9613: comparison with measurements. Applied Acoustics, 65, pp. 883-892, 2004. doi:10.1016/j.apacoust.2004.03.004

[14] King, E.A. \& Rice, H.J., The development of a practical framework for strategic noise mapping. Applied Acoustics, 70, pp. 1116-1127, 2009. doi:10.1016/j.apacoust.2009.01.005

[15] ISO 9613-2. Acoustics - attenuation of sound during propagation outdoors - Part 2: General method of calculation; 1996.

[16] King, E.A. \& Rice, H.J., The development of a practical framework for strategic noise mapping. Applied Acoustics, 70, pp. 1116-1127, 2009. doi:10.1016/j.apacoust.2009.01.005 